\title{
Culinary Decoctions: Spectrophotometric Determination of Various Polyphenols Coupled with their Antioxidant Activities
}

\author{
Fatiha El Babili $^{1,2, *}$, Mohammed E.L. Babili ${ }^{3}$, Jean-Pierre Souchard ${ }^{2}$ and Christian Chatelain ${ }^{1}$
}

${ }^{1}$ Faculté des Sciences Pharmaceutiques de Toulouse - Laboratoire de Botanique - Faculté de Pharmacie, 35 ch. des
Maraîchers - F- 31062 Toulouse, France; ${ }^{2}$ Laboratoire des Interactions Moléculaires et Réactivité Chimique et Photo-
chimique UMR CNRS 5623, Université de Toulouse, 118 Route de Narbonne, F-31062 Toulouse Cedex 9 , France;
${ }^{3}$ Institut Michel Pacha, Université Claude Bernard Lyon I, La Seyne sur Mer, France

Abstract: The aqueous extracts of sweet basil (Ocimum basilicum L.), tarragon (Artemisia dracunculus L.), fennel (Foeniculum vulgare Miller), olive (Olea europaea L.), sage (Salvia officinalis L.), thyme (Thymus vulgaris L.), wild thyme (T. serpyllum L.), tea (Camellia sinensis (L.) Kuntze), and verbena (Verbena officinalis L.) were investigated for polyphenol, tannins, antocyanins and flavonoids. Among the nine culinary herbs, tea and wild thyme extracts contained the higher phenol content of $874.10 \pm 3.50 \mathrm{GAE}$ [g gallic acid equivalents $/ \mathrm{Kg}$ (dry wt.) extract] and $945.70 \pm 0.81 \mathrm{GAE}$, respectively, while the fennel extract contained the lowest content at 149.90 \pm 1.16 GAE. Sage and verbena extracts do not contain any anthocyanins and have low levels of tannins $(2.40 \pm 0.12$ and $1.97 \pm 0.06 \mathrm{CE}$, respectively). Tea rich in tannins and verbena and sage, totally devoid of anthocyanins, have higher antioxidant activities according to the ABTS/DPPH assays. However, the results fail to show any positive correlation between phenol contents and antioxidant activities.

Keywords: Culinary herbs, polyphenols, anthocyanins, flavonoids, decoction, ABTS, DPPH assays.

\section{INTRODUCTION}

Culinary or dietary herbs are often consumed in various cultures. These herbs are rich in polyphenolics and their protective effects of phenolic on some diseases have been recognized due to their antioxidant activities [1]. The major anti-oxidant compound of sweet basil (Ocimum basilicum L., Lamiaceae), used worldwide for its gustative qualities, is rosmarinic acid [2]. In Europe, Artemisia dracunculus L. (Asteraceae) called "tarragon", is popularly used because of its biological properties $[3,4]$. The seed methanol extract of fennel (Foeniculum vulgare Miller, Apiaceae) [5, 6] showed a remarkable anticancer potential [7] and antioxidant activity [8]. Mediterranean diet, rich in olive (Olea europaea L., Oleaceae) oil, is associated with the lower incidence of cardio-vascular disease, cancer [9] because its phenols are powerful antioxidants [10]. Common sage (Salvia officinalis L., Lamiacaeae), used for hundreds of years in natural medicine, contains rosmarinic acid as its major phenolic antioxidant [11]. Thyme (Thymus vulgaris L., Lamiaceae) is an aromatic and medicinal plant because of its polyphenols, namely rosmarinic acid, flavonoids and vitamin E. Wild thyme (T. serpyllum L.), also contains rosmarinic acid as one of its main compounds [12]. A number of studies during the last decade have linked tea (Camellia sinensis (L.) Kuntze, Theaceae) consumption, especially green tea, to a reduced risk for cancer in humans [13] leading to increased popularity of tea as a health drink. Verbena (Verbena officinalis L., Verbenaceae)

*Address correspondence to this author at the Laboratoire de Botanique, Faculté de Pharmacie, Université de Toulouse, 118 Route de Narbonne, F31062 Toulouse Cedex 9, France; Tel: +33562259817;

E-mail: fatiha.el-babili@univ-tlse3.fr aqueous extracts represent a good source of antioxidant (three iridoids, fifteen flavonoids and four phenolic acid derivatives) [14].

In fact, the increase on the demand for natural bioactive compounds used in food industry for the preservation of food quality has led to an exhaustive search of new sources. The strong protective effects of tea infusions (oregano, thyme and wild thyme) were proposed to be the consequence of large amounts of polyphenols, namely rosmarinic acid and flavonoids. Although several culinary herbs (e.g., Ocimum basilicum, Foeniculum vulgare, Salvia officinalis) were well investigated for their chemical constituents and antioxidant activities [15], little work has been done on their decoctions, which have been used most traditionally in many countries. Our investigation on "culinary herbs" was to study the chemical compositions of their aqueous extracts in polyphenols, tannins, anthocyanins, and flavonoids and to evaluate qualitatively (by TLC bioautography) and quantitatively (by DPPH/ABTS assays) their antioxidant properties.

\section{MATERIALS AND METHODS}

\section{Plant Materials}

The culinary herbs used are: sweet basil (Ocimum basilicum L.), tarragon (Artemisia dracunculus L.), fennel (Foeniculum vulgare Miller), olive (Olea europaea L.), sage (Salvia officinalis L.), thyme (Thymus vulgaris L.), wild thyme (T. serpyllum L.), tea (Camellia sinensis (L.) Kuntze), and verbena (Verbena officinalis L.). The Botanical garden and laboratory of Toulouse provided the dried herbs. Christian Châtelain and Fatiha EL Babili identified the plants and voucher specimen were deposited at the herbarium of the Laboratory of botanic. 


\section{Preparation of Extracts}

Each ground sample $(50 \mathrm{~g})$ was added to $500 \mathrm{~mL}$ of distilled water, and heated (heating plate, Fisher Scientific) until boiling. The mixture was left at boiling temperature for 10 min; then filtered under reduced pressure after at room temperature for $5 \mathrm{~min}$. The obtained decoction was frozen, lyophilized (GAMA Christ Freeze Dryers) and re-dissolved in water at concentration of $0.58 \mathrm{mg} / \mathrm{mL}$ for basil, 2.005 $\mathrm{mg} / \mathrm{mL}$ for fennel and $1.92 \mathrm{mg} / \mathrm{mL}$ for the other herbs to study their chemical composition. The various concentrations were chosen for a visual colorimetric DPPH assay.

\section{Reagents}

All chemicals used were of analytical reagent grade. All reagents were purchased from Sigma-Aldrich, Fluka (SaintQuentin France).

\section{Total Phenolics}

The total phenolic amount of each extract was determined by the Folin-Ciocalteu method [16]. A diluted solution of each extract $(0.5 \mathrm{~mL})$ was mixed with Folin Ciocalteu reagent $(0.2 \mathrm{~N}, 2.5 \mathrm{~mL})$. This mixture was allowed to stand at room temperature for $5 \mathrm{~min}$ and then sodium carbonate solution $(75 \mathrm{~g} / \mathrm{L}$ in water, $2 \mathrm{~mL})$ was added. After $1 \mathrm{~h}$ of incubation, the absorbance was measured at $765 \mathrm{~nm}$ against blank using a Helios spectrophotometer (Unicam, Cambridge, UK). A standard calibration curve was plotted using gallic acid (0-300 $\mathrm{mg} / \mathrm{L})$. Results were expressed as $\mathrm{g}$ of gallic acid equivalents (GAE)/Kg of dry mass.

\section{Condensed Tannin Contents}

Catechins and proanthocyanidins reactive with vanillin were analyzed by the vanillin method [17]. One milliliter (1 $\mathrm{mL}$ ) of each extract solution was mixed in a test tube with 2 $\mathrm{mL}$ of vanillin $\left(1 \%\right.$ in $\left.7 \mathrm{M} \mathrm{H}_{2} \mathrm{SO}_{4}\right)$ in an ice bath. Then the mix was incubated at $25^{\circ} \mathrm{C}$. After 15 minutes, the solution absorbance was read at $500 \mathrm{~nm}$. Concentrations were calculated as $\mathrm{g}$ catechin equivalents $(\mathrm{CE}) / \mathrm{Kg}$ dry mass from a calibration curve.

\section{Total Flavonoids}

The total flavonoids were estimated according to the Dowd method as adapted by Arvouet-Grand [18]. A diluted methanolic solution $(4 \mathrm{~mL})$ of each extract was mixed with a solution $(4 \mathrm{~mL})$ of aluminium trichloride $\left(\mathrm{AlCl}_{3}\right)$ in methanol (2\%). The absorbance was read at $415 \mathrm{~nm}$ after 15 minutes against a blank sample consisting of a methanol $(4 \mathrm{~mL})$ and extract $(4 \mathrm{~mL})$ without $\mathrm{AlCl}_{3}$. Quercetin was used as reference compound to produce the standard curve, and the results were expressed as $g$ of quercetin equivalents $(\mathrm{QE}) / \mathrm{Kg}$ of dry mass.

\section{Total Anthocyanins}

Total anthocyanin content was measured with the $\mathrm{pH}$ differential absorbance method, as described by Cheng and Breen [19]. Briefly, absorbance of the extract was measured at 510 and $700 \mathrm{~nm}$ in buffers at $\mathrm{pH} 1.0$ (hydrochloric acidpotassium chloride, $0.2 \mathrm{M}$ ) and 4.5 (acetate acid-sodium acetate, $1 \mathrm{M}$ ). The wavelength reading was performed after 15 minutes of incubation. Anthocyanin content was calculated using a molar extinction coefficient $(\varepsilon)$ of 29600 (cyanidin-3-glucoside $)$ and absorbance of $\mathrm{A}=\left(\left(\mathrm{A}_{510}-\mathrm{A}_{700}\right) \mathrm{pH} 1.0\right.$ - $\left.\left(\mathrm{A}_{510}-\mathrm{A}_{700}\right) \mathrm{pH} 4.5\right)$. Results were expressed as mg cyanidin-3-glucoside equivalent (C3GE) / Kg of dry mass.

\section{TLC Bioautography Method}

An aliquot of aqueous solution of the nine medicinal herbs studies $(40 \mu \mathrm{L})$ was directly deposited (as spots or bands) onto silica gel 60F254 TLC plates (Merck, Germany) (20). TLC plates were developed to a distance of $75 \mathrm{~mm}$, in a $20 \mathrm{~cm} \times 20 \mathrm{~cm}$ glass flat-bottom chamber after equilibration with mobile phase vapor for $30 \mathrm{~min}$ with ethyl acetateformic acid-acetic acid-water (100:11:11:26) as developing reagents. The developed TLC plates were then removed from the chamber and air-dried in an aerator at room temperature. The plates were then colorized by spraying with $0.04 \%$ DPPH-methanol solution (20 mg DPPH dissolved in $50 \mathrm{~mL}$ methanol) for $5 \mathrm{~s}$. and heated at $40{ }^{\circ} \mathrm{C}$ on a plate heater for $30 \mathrm{~min}$. Extracts antiradical activity were estimated from the intensity of disappearance of the violet/purple background of the plate. Free radical scavenging zones were qualitatively identified immediately as yellow areas against a light violet/purple background. Each TLC plate was then monitored under Visible light and photographed (Camag TLC under software control).

\section{DPPH Assays}

Antioxidant scavenging activity was studied using 1,1diphenyl-2-picrylhydrazyl free radical (DPPH) as described by Blois [21] with some modifications; $1.5 \mathrm{~mL}$ of various dilutions of the test materials (essential oil or plant extracts) were mixed with $1.5 \mathrm{~mL}$ of a $0.2 \mathrm{mM}$ methanolic DPPH solution. After an incubation period of 30 minutes at $25^{\circ} \mathrm{C}$, the absorbance at $520 \mathrm{~nm}$, the wavelength of maximum absorbance of DPPH, were recorded as $\mathrm{A}_{(\text {sample) }}$, using a Helios spectrophotometer (Unicam, Cambridge, UK). A blank experiment was also carried out applying the same procedure to a solution without the test material and the absorbance was recorded as $\mathrm{A}_{\text {(blank). }}$ The free radical-scavenging activity of each solution was then calculated as percent inhibition according to the following equation:

$$
\% \text { inhibition }=100\left(\mathrm{~A}_{(\text {blank })}-\mathrm{A}_{(\text {sample })}\right) / \mathrm{A}_{(\text {(blank }}
$$

Antioxidant activity of extracts was expressed as $\mathrm{IC}_{50}$, defined as the concentration of the test material required to cause a 50\% decrease in initial DPPH concentration. Ascorbic acid was used as a standard. All measurements were performed in triplicate.

\section{ABTS Assay}

The radical scavenging capacity of the samples for the ABTS (2,2'-azinobis-3-ethylbenzothiazoline-6-sulphonate) radical cation was determined as described by $\operatorname{Re}$ [22]. ABTS was generated by mixing a $7 \mathrm{mM}$ of ABTS at $\mathrm{pH} 7.4$ ( $5 \mathrm{mM} \mathrm{NaH}_{2} \mathrm{PO}_{4}, 5 \mathrm{mM} \mathrm{Na} 2 \mathrm{HPO}_{4}$ and $154 \mathrm{mM} \mathrm{NaCl}$ ) with $2.5 \mathrm{mM}$ potassium persulfate (final concentration) followed by storage in the dark at room temperature for $16 \mathrm{~h}$ before use. The mixture was diluted with ethanol to give an absor- 
bance of $0.70 \pm 0.02$ units at $734 \mathrm{~nm}$ using a spectrophotometer. For each sample, diluted methanol solution of the sample $(100 \mu \mathrm{L})$ was allowed to react with fresh ABTS solution $(900 \mu \mathrm{L})$, and then the absorbance was measured 6 minutes after initial mixing.

Ascorbic acid was used as a standard and the capacity of free radical scavenging was expressed by $\mathrm{IC}_{50}(\mathrm{mg} / \mathrm{L})$ values calculated, denoting the concentration required to scavenge $50 \%$ of ABTS radicals. The capacity of free radical scavenging $\mathrm{IC}_{50}$ was determined using the same previously used equation for the DPPH method. All measurements were performed in triplicate.

\section{Statistical Analysis}

All data were expressed as means \pm standard deviations of triplicate measurements. The confidence limits were set at $\mathrm{P}<0.05$. Standard deviations (SD) did not exceed 5\% for the majority of the values obtained.

\section{RESULTS AND DISCUSSION}

\section{Chemical Compositions}

The chemical composition of the nine decoctions studied was evaluated (Table 1). Total amount of flavonoids, in thyme aqueous extract, was the higher $(398 \pm 1.2 \mathrm{~g} / \mathrm{kg}$ equivalent quercetin), while wild thyme aqueous extract was the richest on polyphenols $(945.70- \pm 0.81 \mathrm{~g} / \mathrm{kg}$ eq gallic acid). The anthocyanins (466.28 $\pm 16.17 \mathrm{mg}$ de cyaniding $/ \mathrm{kg}$ ) were present in higher content in basil aqueous extract. The tannins exist in all extracts with an amount between $1.93 \pm 0.26$ (basil) to $11.30 \pm 0.17$ (tea) eq catechin $(\mathrm{g} / \mathrm{Kg}$ dry). The chemical composition study of culinary herbs allows us to begin to understand their properties.

\section{Antioxidant Capacities}

TLC combined with DPPH bioautography assay in situ is the analytical qualitative method we used to choose the plants to study before DPPH and ABTS assays (Figs. 1 and 2). In TLC (Fig. 1) we can see that all the herbs studied here exhibit an antioxidant profile. Free radical scavenging zones were identified, qualitatively, immediately as yellow areas against a light violet/purple background. In a second TLC (Fig. 2), we begun to explore the complexity of the studied decoctions, work will led us to further identification.

In our study, the culinary herbs antioxidant activity (Table 2) showed for verbena aqueous extract an $\mathrm{IC}_{50}$ of $15.76 \pm 0.8 \mathrm{mg} / \mathrm{L}$ in DPPH radical scavenging assay and $\mathrm{IC}_{50}$ of $16.55 \pm 1.1 \mathrm{mg} / \mathrm{L}$ in ABTS radical scavenging assay. The sage aqueous extract exhibited an $\mathrm{IC}_{50}$ of $11.06 \pm 0.7 \mathrm{mg} / \mathrm{L}$ in DPPH and with $\mathrm{IC}_{50}$ of $25.68 \pm 0.9 \mathrm{mg} / \mathrm{L}$ in ABTS radical scavenging assay. Wild thyme aqueous extract was the less active extract. The tea decoction was the most active extract with an $\mathrm{IC}_{50}$ of $8.19 \pm 0.2 \mathrm{mg} / \mathrm{L}$ in DPPH and with $\mathrm{IC}_{50}$ of $33.65 \pm 2.7 \mathrm{mg} / \mathrm{L}$ in ABTS radical scavenging assay. This approach will guide us in finding the best potential in terms of chemical families and activities searched, knowing that tests remain the safest way.

Decoction was the main form used in traditional medicine. Given its ease of use, this result confirms the traditional use of culinary herbs in the world, thus highlighting their potential in health.

Antioxidants acting as radical scavengers are able to protect the human body as well as processed foods from oxidative damage. Medicinal plants represent a diverse group of herbs spread throughout the world with a high content of bioactive compounds possessing a variety of biological activities. Presently much attention has been focused to the antioxidant effect of plant natural compounds because of their wide application in food. Medicinal plants, being a promising source of phenolics, flavonoids, anthocyanins and carotenoids, are usually used for adding flavor and improve the shelf life of dishes and processed food products. Regarding these beneficial effects, low cost and properties of plant phenolics, the interest is to increase research natural antioxidants, in order to develop their use in the food

Table 1. Composition of "Culinary" Aqueous Extracts

\begin{tabular}{|c|c|c|c|c|}
\hline Aqueous extracts & $\begin{array}{c}\text { Polyphenols } \\
\text { (eq Gallic acid) }\end{array}$ & $\begin{array}{c}\text { Tannins } \\
(\text { eq Catechin) }\end{array}$ & $\begin{array}{c}\text { Flavonoids } \\
(\text { eq Quercetin) }\end{array}$ & $\begin{array}{c}\text { Anthocyanins } \\
(\text { eq cyanindin) }\end{array}$ \\
\hline Basil & $265.20 \pm 1.61$ & $1.93 \pm 0.26$ & $107.06 \pm 5.6$ & $466.28 \pm 16.15$ \\
\hline Tarragon & $177.50 \pm 1.40$ & $4.10 \pm 0.16$ & $167.31 \pm 2.6$ & $285.06 \pm 34.05$ \\
\hline Fennel & $149.90 \pm 1.16$ & $7.15 \pm 0.06$ & $110.44 \pm 3.9$ & $106.12 \pm 8.16$ \\
\hline Olive & $370.30 \pm 1.00$ & $9.21 \pm 0.33$ & $259.62 \pm 2.3$ & $58.56 \pm 5.34$ \\
\hline Sage & $699.90 \pm 2.27$ & $2.40 \pm 0.12$ & $195.74 \pm 1.2$ & 0 \\
\hline Wild thyme & $945.70 \pm 0.81$ & $6.89 \pm 0.14$ & $180.58 \pm 1.7$ & $312.13 \pm 47.71$ \\
\hline Tea & $874.10 \pm 3.50$ & $11.30 \pm 0.17$ & $398.57 \pm 1.2$ & $93.77 \pm 8.52$ \\
\hline Thyme & $648.0 \pm 8.86$ & $4.70 \pm 0.07$ & $188.90 \pm 2.5$ & $213.60 \pm 18.03$ \\
\hline Verbena & $652.50 \pm 2.36$ & $1.97 \pm 0.06$ & \\
\hline
\end{tabular}

${ }^{\mathrm{a}}: \mathrm{g} / \mathrm{Kg} \mathrm{dry} ;{ }^{\mathrm{b}}: \mathrm{mg} / \mathrm{Kg}$ dry 


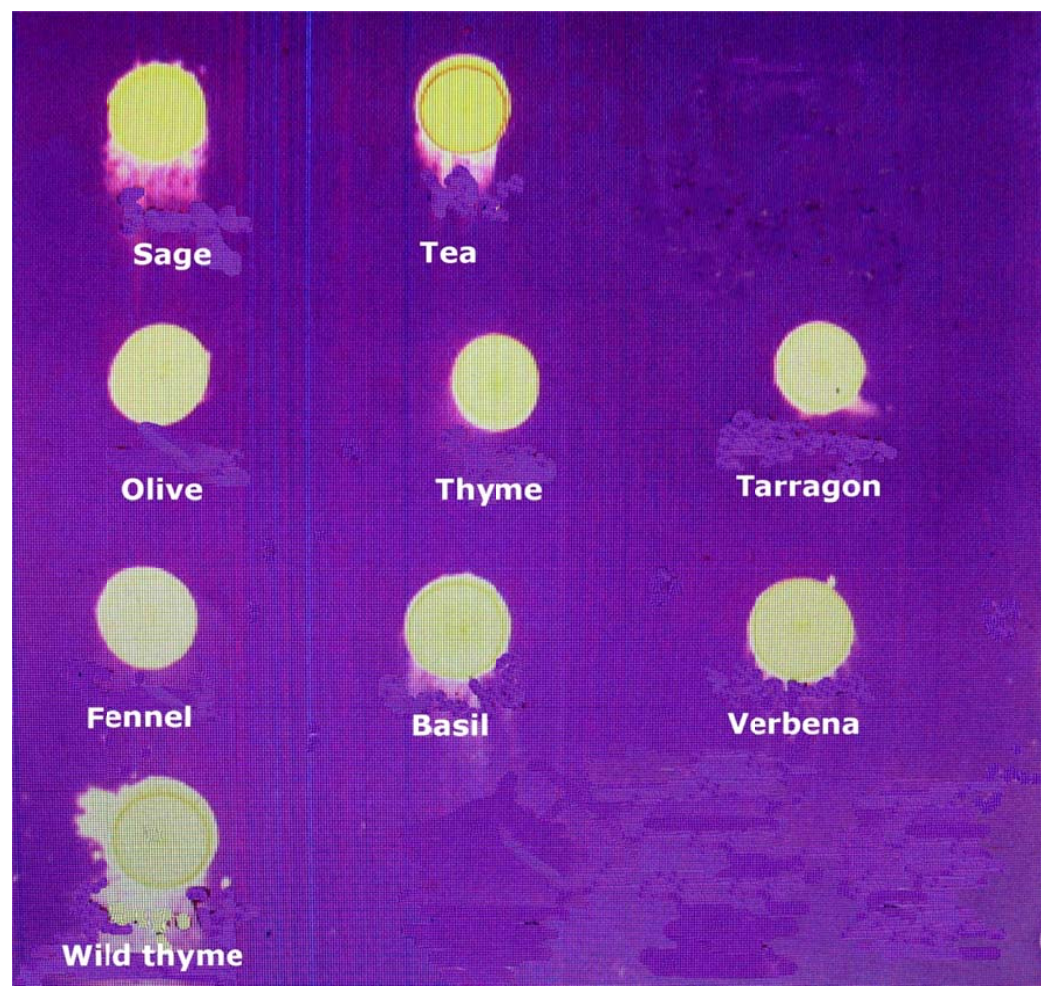

Fig. (1). Typical TLC photography of decoctions of 9 Provencal and Culinary Herbs colorized by spraying with $0.04 \%$ DPPH-methanol solution.

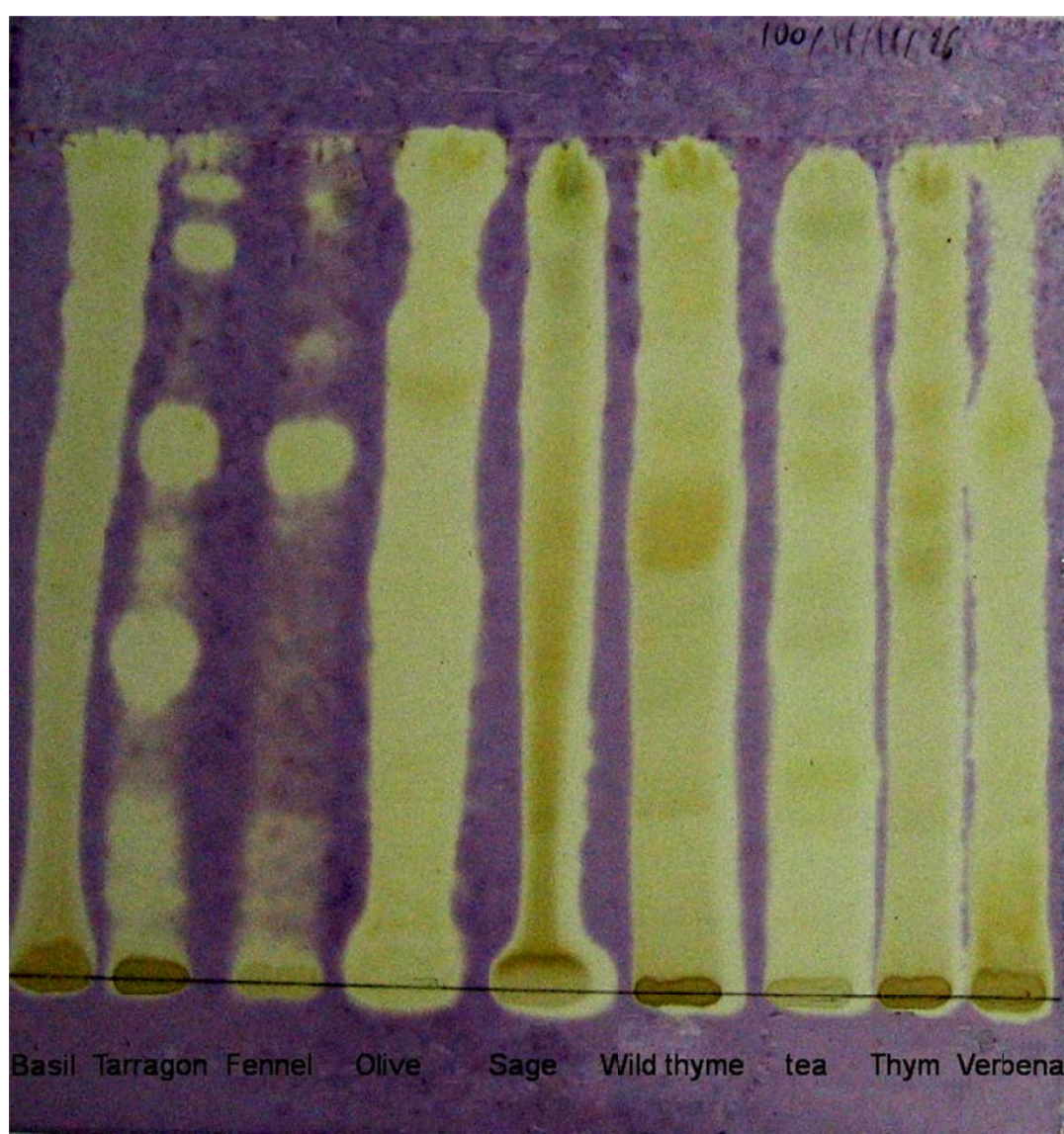

Fig. (2). Typical TLC photography of decoctions of 9 Provencal and Culinary Herbs developed and colorized by spraying with $0.04 \%$ DPPHmethanol solution from four species of. 
Table 2. “Culinary” Aqueous Extracts Antioxidant Activity

\begin{tabular}{|c|c|c|}
\hline Type of extract & $\begin{array}{l}\text { ABTS assay } \\
\operatorname{IC}_{50}(\mathrm{mg} / \mathrm{L})\end{array}$ & $\begin{array}{l}\text { DPPH assay } \\
\mathrm{IC}_{50}(\mathrm{mg} / \mathrm{L})\end{array}$ \\
\hline Basil & $152.23 \pm 2.6$ & $39.77 \pm 0.2$ \\
\hline Tarragon & $56.89 \pm 2.3$ & $35.42 \pm 0.6$ \\
\hline Fennel & $123.66 \pm 1.5$ & $107.7 \pm 2.3$ \\
\hline Sage & $25.68 \pm 0.9$ & $11.06 \pm 0.7$ \\
\hline Wild thyme & $212.45 \pm 1.6$ & $157.85 \pm 1.8$ \\
\hline Tea & $33.65 \pm 2.7$ & $8.19 \pm 0.2$ \\
\hline Thyme & $106.55 \pm 1.3$ & $22.35 \pm 1.52$ \\
\hline
\end{tabular}

industry and preventive medicine. The antioxidant capacity measured by DPPH assay was highly correlated with the amount of total phenols as our results show for tea and sage.

The decoction of tea has an antioxidant activity with results close to those of vitamin $\mathrm{C}$. These results will allow a wiser and greener use of our rich botanical heritage. Improved knowledge on the chemical composition and antioxidant properties of decoctions used in traditional medicine could be a solution in search of alternatives and / or supplements for chemicals available.

The plants that we studied are widely used around the world and the heart of a thriving market. Only the form usually used, ie, the decoction is studied here because we wanted to highlight the traditional and current use. Although rosmarinic acid, a powerful antioxidant compound, is present in basil, sage, thyme and thyme, It was tea and verbena decoctions, which had the highest antioxidant activity with an $\mathrm{IC}_{50}$ of $8.19 \pm 0.2 \mathrm{mg} / \mathrm{L}$ and an $\mathrm{IC}_{50}$ of $15.76 \pm 0.8 \mathrm{mg} /$ $\mathrm{L}$, respectively. On the one hand, tea chemically different from other aqueous extracts by its richness tannin (catechin equivalent $11.30 \mathrm{~g} / \mathrm{kg}$ ). On the other hand, sage and verbena, the other two plants with high antioxidant activity, show a total lack of anthocyanins in their chemical composition. This work reveals the importance of the knowledge of the chemical composition of traditional decoctions and / or commonly used and justifies our interest in this subject. Indeed, our results show that the presence of an antioxidant compound is not enough to justify an antioxidant property for a decoction.

\section{CONFLICT OF INTEREST}

The author(s) confirm that this article content has no conflicts of interest.

\section{ACKNOWLEDGEMENT}

Declared none.

\section{ABBREVIATIONS}

ABTS = 2,2'-Azinobis-3-ethylbenzothiazoline-6sulphonate

$\mathrm{DPPH}=1,1$-Diphenyl-2-picrylhydrazyl

GAE = Gallic acid equivalents

$\mathrm{QE} \quad=$ Quercetin equivalents

TLC = Thin layer chromatography

\section{REFERENCES}

[1] Gross, M. Flavonoids and cardiovascular disease. Pharm. Biol., 2004, 42 (suppl.), 21-35.

[2] Park, J. B. Identification and quantification of a major anti-oxidant and anti-inflammatory phenolic compound found in basil, lemon thyme, mint, oregano, rosemary, sage, and thyme. Int. J. Food Sci. Nutr., 2011, 62 (6), 577-584.

[3] Uhl, S.R.; Strauss, S. Handbook of Spices, Seasonings and Flavorings; Technomic Publishing: Lancaster, PA, 2000, 170-171.

[4] Benli, M.; Kaya, I.; Yigit, N. Screening antimicrobial activity of various extracts of Artemisia dracunculus L. Cell Biochem. Funct., 2007, 25 (6), 681-686.

[5] Bilia, A.R.; Fumarola, M.; Gallori, S.; Mazzi, G.; Vincieri, F. Identification by HPLC-DAD and HPLC-MS analyses and quantification of constituents of fennel teas and decoctions. J. Agric. Food Chem., 2000, 48, 4734-4738.

[6] Choi, E.M.; Hwang, J.K. Antiinflammatory, analgesic and antioxidant activities of the fruit of Foeniculum vulgare. Fitoterapia, 2004, 75, 557-565.

[7] Mohamad, R.H.; El-Bastawesy, A.M. Antioxidant and anticarcinogenic effects of methanolic extract and volatile oil of fennel seeds (Foeniculum vulgare). J. Med. Food, 2011, 14, 986-1001.

[8] Oktay, M.; Gülçin, I.; Küfreviog, I. Determination of in vitro antioxidant activity of fennel (Foeniculum vulgare) seed extracts. Lebensm.-Wiss. Technol., 2003, 36, 263-271.

[9] Fung, T.T.; Rexrode, K.M.; Mantzoros, C.S.; Manson, J.E. Willett, W.C. Hu, F.B. Mediterranean diet and incidence of and mortality from coronary heart disease and stroke in women. Circulation. 2009, 119, 1093-1100.

[10] Djenane, D.; Yanguela, J.; Roncales, P. Antioxidant activity of crude extract from Algerian chemlal olive leaves and application in stored meat. Planta Med. , 2011, 77, 1407-1407.

[11] Qnais, E. Y.; Abu-Dieyeh, M.; Abdulla, F.A. The antinociceptive and anti-inflammatory effects of Salvia officinalis leaf aqueous and butanol extracts. Pharm. Biol., 2010, 48, 1149-1156. 
[12] Miron, T.L.; Plaza, M.; Bahrim, G.; Ibáñez, E. ; Herrero, M. Chemical composition of bioactive pressurized extracts of Romanian aromatic plants. J. Chromatogr. A, 2011, 1218, 4918-4927.

[13] Kuroda, Y.; Hara, Y. Antimutagenic and anticarcinogenic activity of tea polyphenols. Mutat. Res., 1999, 436, 69-97.

[14] Rehecho, S.; Hidalgo, O.; García-Iñiguez, C. M.; Navarro, I.; Astiasarán, I.; Ansorena, D.; Yolanda, C. R.; Isabel, C. M. Chemical composition, mineral content and antioxidant activity of Verbena officinalis L. LWT. Food Sci. Technol., 2011, 44, 875-882.

[15] Shivmurat, Y.S.; Usha, M. Antioxidant activity of Ocimum basilicum and Salvia officinalis. Res. J. Biotechnol., 2011, 6(3), 22-25.

[16] Folin, O.; Ciocalteu. V. On tyrosine and tryptophane determination in proteins. J. Biol. Chem., 1927, 27, 627-650.

[17] Naczk, M.; Amarowicz, R.; Pink, D.; Shahidi, F. Insoluble condensed tannins of canola/rapeseed. J Agric Food Chem, 2000, 48, $1758-1762$.
[18] Arvouet-Grand, A. ; Vennat, B. ; Pourrat, A. ; Legret, P. Standardisation d'un extrait de propolis et identification des principaux constituants. J. Pharm. Belg., 1994, 49, 462-468.

[19] Cheng, G.W.; Breen, P.J. Cell count and size in relation to fruit size among strawberry cultivars. J. Amer. Soc. Hort. Sci., 1991, 117, 946-950.

[20] Jin Wang, Yong-De Yue *, Feng Tang and Jia Sun TLC Screening for Antioxidant Activity of Extracts from Fifteen Bamboo Species and Identification of Antioxidant Flavone Glycosides from Leaves of Bambusa. textilis McClure Molecules 2012, 17, 12297-12311

[21] Blois, M.S. Antioxidant determinations by the use of a stable free radical. Nature, 1958, 181, 1199-1150.

[22] Re, R.; Pellegrini, N.; Proteggente, A.; Pannala, A.; Yang, M.; Rice-Evans, C. Antioxidant activity applying an improved ABTS radical cation decolorization assay. Free Rad. Biol. Med., 1999, 26, 1231-1237.

(C) El Babili et al.; Licensee Bentham Open.

This is an open access article licensed under the terms of the Creative Commons Attribution Non-Commercial License (http://creativecommons.org/licenses/by-nc/3.0/) which permits unrestricted, non-commercial use, distribution and reproduction in any medium, provided the work is properly cited. 